\title{
Implementation of Open Space: The Need for Uniform Policy
}

\author{
Putri Haryati Ibrahim ${ }^{1}$, Melasutra Md Dali ${ }^{2} \&$ Safiah Yusmah Muhammad Yusoff ${ }^{3}$ \\ ${ }^{1}$ Department of Landscape Architecture, Kulliyyah of Architecture and Environmental Design, International \\ Islamic University, Kuala Lumpur, Malaysia \\ ${ }^{2}$ Department of Urban \& Regional Planning, Faculty of Built Environment Building, University of Malaya, \\ Kuala Lumpur, Malaysia \\ ${ }^{3}$ Department of Geography, Faculty of Arts and Social Sciences University of Malaya, Kuala Lumpur, Malaysia \\ Correspondence: Putri Haryati Ibrahim, Department of Landscape Architecture, Kulliyyah of Architecture and \\ Environmental Design, International Islamic University, O. Box 10, 50728 Kuala Lumpur, Malaysia. E-mail: \\ putri@iium.edu.my
}

\author{
Received: April 2, 2013 Accepted: April 26, 2013 Online Published: June 1, 2013 \\ doi:10.5539/jsd.v6n7p16 URL: http://dx.doi.org/10.5539/jsd.v6n7p16
}

\begin{abstract}
The provision of open spaces within a residential development is often seen as unimportant. The Malaysian Government targeted to provide 2 hectares of open space per 1000 population to be achieved as a developed nation status by the year 2020. This vision can be seen as the Government attempt to ensure the sustainability of open spaces in Malaysia. The Federal Department of Town and Country Planning, Peninsular Malaysia (FDTCP) has produced a planning standard guideline to supervise the implementation of the open space policy in Malaysia. According to FDTCP; until December 2009, Malaysia has achieved a percentage of 1.19 hectares of open space per 1000 population. Achieving the standard requires commitment of local authorities to implement the open space policy. However, the adoption of open spaces policy differs among local authorities, from a simplistic general approach of land ratio techniques to an ergonomics method. The paper examines the local allocation practices using 5 different approaches and it argues that implementation of open space by local planning practices requires the knowledge of and understanding by planning profession towards a long term sustainable green objectives.
\end{abstract}

Keywords: open space policy, residential development, urban planning, local authority planning, environment sustainability

\section{Introduction}

The importance of open areas or open spaces has been widely covered by writers and researchers. This is because open spaces provide huge benefit to human lives in terms of quality of life. However, a review by Luqman et al. (1999) highlights the fact that developments in cities are being designed solely to emphasize commercial values and profits. Green spaces are sacrificed to make way for the development in cities. This has resulted in the neglected interest and welfare of city dwellers as the developers' main focus is to reap maximum return on investment. By and large, developers have not been adequately providing open spaces for city dwellers for outdoor activities. Sometimes the provision of open spaces is merely to meet the approval requirements set by state governments and local authorities (LA's). Therefore, it is important that the state governments in Malaysia ensure that the implementation policy for its open spaces is in accordance the provision with the Planning Standard Guidelines for Open Spaces and Recreation (JBPD 7/2000) issued by the Federal Department of Town and Country Planning, Peninsular Malaysia (FDTCP). The commitment by each LA to implement the open space policy within their respective jurisdiction is a key step in ensuring that the provision for open spaces is not ignored by the developers in their proposed developments. Thus, the research will be focusing into the aspect of policy implementation by the decision maker and planning administrative at the local level. Emphasis on the implementation and application of open space policy is the first step taken before a development can be approved. Therefore, strong enforcement by the LAs will is highly needed to ensure the sustainability of open spaces will be more secure. 


\section{Literature Review}

It is believed that the term 'open space' was first used in 1833 by a committee in a "public trail" in London. This committee is also believed to be the agency responsible for creating the term 'open spaces' (Maruani and Amit-Cohen, 2007, p. 4). The usability and design of open spaces evolved in line with the developments and trends of the times. Today, the term 'open spaces' is adopted worldwide as areas for various activities such as recreation and as places to meet and socialize. In the Malaysian local context, the definition of open spaces under Section 2 (1) Town and Country Planning Act 1976 (Act 172) is "any land that is enclosed or not enclosed, for use or reserved for the use in whole or in parts as public gardens, public parks, public sports and recreational fields, tourism areas, pathways or public places" (p. 15). In general, open spaces can be considered as an open area designated for the public to carry out their recreational activities. Grose (2009) has similar views with regards to the definition of open spaces as that in Act 172, and defines open spaces as 'public spaces'. It can be deduced from the definitions in Act 172 and writings of Grose that open spaces are areas built for public recreational purposes. Thus, it should be noted that the term 'open spaces' used in this paper refers to the open spaces in residential areas provided for the public use of recreational activities.

\subsection{Conservation of Open Space as a Tool for Sustainable Development}

It is widely known when a new development occurs it involves the opening of an area. The total area of development is based on the capital and the greatness of the project to be developed. If the development occurred on the outskirts of town; the problem of land is not a big issue. However, if the location of the project is in the city centre, developer will face a problem to find a suitable location. Review of Girling and Helphand (1994) indicates that green space is gradually decreasing in addition to the development of more houses especially in urban area. This situation is in line with the current situation in Malaysia in which the urban population will increase up to 70 percent by the year 2020 (Department of Statistics Malaysia, 2000). Review of Bengston, Fletcher et al. (2004), states open space protection is the main issue of sustainable development. This is because to achieve the objective of sustainable development, it should have some allocation of open spaces for public use. Developers are required to provide open spaces and greenery in each development undertaken. This is important for the fact that people need open spaces to perform outdoor activities while green areas are necessary to act as a buffer zone and green belt area. Open spaces provision indirectly provides 'balance' between development and environmental protection. Thus it appears clearly that conservation of open space is one of the right ways to accomplish sustainable development. Therefore, preservation of such spaces is highly important to ensure a better quality of life can be achieved.

\subsection{Existing Policy for Open Spaces in Malaysia}

As a result of rapid development urban areas are experiencing a critical shortage of green areas. Thus, for every development within and near urban areas, the location and allocation of open spaces must be seriously considered by the authorities to prevent the reduction in the urban green areas due to development. To realise the concept of "a city in a park" mooted by the former Prime Minister of Malaysia, His Excellency Tun Dr Mahathir Mohamad, FDTCP issued a general guideline which is the JBPD 7/2000. The main objective of the guideline is to assist state governments through their respective LAs to achieve the vision in making Malaysia a "Garden Nation". The intention of the guideline is to assist town planners, developers, and the general public to better understand the key issues of open spaces with respect to financial provisions, sizes, definitions, usage, and design requirements that must be met. With respect to open spaces, the Town and Country Planning Act 1976 (Act 172) is important and relevant as open spaces are clearly defined in this Act. As stated in Section 2.0, a clear description of what constitutes 'open spaces' in Act 172 is vital as it serves as the basis of reference in defining the true meaning of open spaces in the Malaysian context. The provisions in the Act seem to be genuine and workable. The approaches and measures by the government in the agenda are to ensure the preservation and sustainability of open spaces and green areas in the country.

Malaysia comprises of 14 states 12 states are located in the Peninsular Malaysia, while Sabah and Sarawak located in Borneo Island. In relation to open space policy, the 11 states in Peninsular Malaysia which are Johor, Kedah, Kelantan, Melaka, Negeri Sembilan, Pahang, Pulau Pinang, Perak, Perlis, Selangor, and Terengganu are bounded by the Act 172 (Town and Country Planning Act 1976) with exception of Federal Territory of Kuala Lumpur, Sabah and Sarawak. The Town and Country Planning Act 1976 (Act 172) was passed by the Malaysian Parliament with the intention to coordinate matters relating to the laws and town and country planning in all the states of Peninsular Malaysia (Lee, Abdul Mutalip et al., 1990; Goh, 1991). The states under Federal Territories (Kuala Lumpur, Labuan and Putrajaya), Sabah and Sarawak, as mentioned uses its own act because the states under the Federal Territories have adopted the Federal Territory Act 1982 (Act 267). Likewise, Sabah and 
Sarawak are not bound by Act 172 because the two states have adopted different acts which is referred to as the Town and Country Planning Ordinance (Sabah Cap.141) and the Town and Country Planning Ordinance (Sarawak Cap.87) (Phang, 2006; Zakaria, 2006; Ainul Jaria \& Bashiran Begum, 2009).

In general, FDTCP has set a policy of 10 percent for open spaces for each development application. However, the 10 percent policy is merely a base reference. According to FDTC (2009), the states bound by Act 172 have the option of implementing the open spaces policy in various ways for development in their respective states. Table 1 shows the guidelines for open spaces adopted by the states that are enacted under Act 172. It is believed that the adoption of open spaces policy differs among LAs within states because many LAs are responsible for all administrative matters at the local level. Each authority has its own guidelines with respect to matters in open spaces. Table 1 present five basic types of approaches that the 11 state governments in Peninsular Malaysia adopt to determine the appropriate guidelines for use in their respective areas.

The approaches can be divided into general, ergonomics space, land ownership, number of housing units, and the size of the development area. The common denominator is the provisions of open spaces, but the approaches differ because of the differences in economic development status, population, demand, and physical locations of the approved areas. Below is a brief discussion of the guidelines:

\subsubsection{General Approach}

The 'general approach' implemented by Negeri Sembilan and Kelantan is based on the basic 10 percent provision of open spaces for all types of residential development. The general approach is applied in total (stand-alone) or as a continuous policy as set by FDTCP.

\subsubsection{Ergonomic Space Approach}

According to the Concise Oxford Dictionary of Current English (1991), ergonomics as in means the study of a person's comfort in their work environment. The ergonomic space approach implemented in Pulau Pinang for the provision of open spaces refers to the measured requirements for an individual to feel comfortable. The measurement for an ideal ergonomic space can be visualised by stretching out both human arms. The ergonomic space with an area of $2 \mathrm{~m} \times 2 \mathrm{~m}$ for each individual is believed to be ample for the individual to move freely and feel comfortable in carrying out activities in open spaces.

\subsubsection{Land Ownership Approach}

Determining the percentage for the provision of open spaces for each development in Terengganu is based on the 'land title'or 'land use' areas to be developed. The 10 percent provision approach is not easy to apply for developments on government land because the LAs are occasionally forced to be lenient towards certain parties who request exemptions.

\subsubsection{Number of Housing Unit Approach}

Perlis, Pahang and Kedah adopt the number of housing unit approach to determine the percentage for the provision of open spaces required of the developer. However, it was discovered that the conditions under which this approach is implemented differ between the three states because the number of developments and population differ greatly.

\subsubsection{Size of Development Area Approach}

There are four states that have adopted the size of development area approach as a method to determine the percentage for the provision of open spaces required of the developers. In Melaka, for developments that achieve the minimum qualification, the provision of open spaces by the developer is at the discretion and goodwill of the LA.While in Selangor, developers are required to pay a contribution to the LA if they cannot meet the provision of open spaces due to limited land or minimum development qualification. 
Table 1. Existing open spaces guidelines in the states of peninsular Malaysia

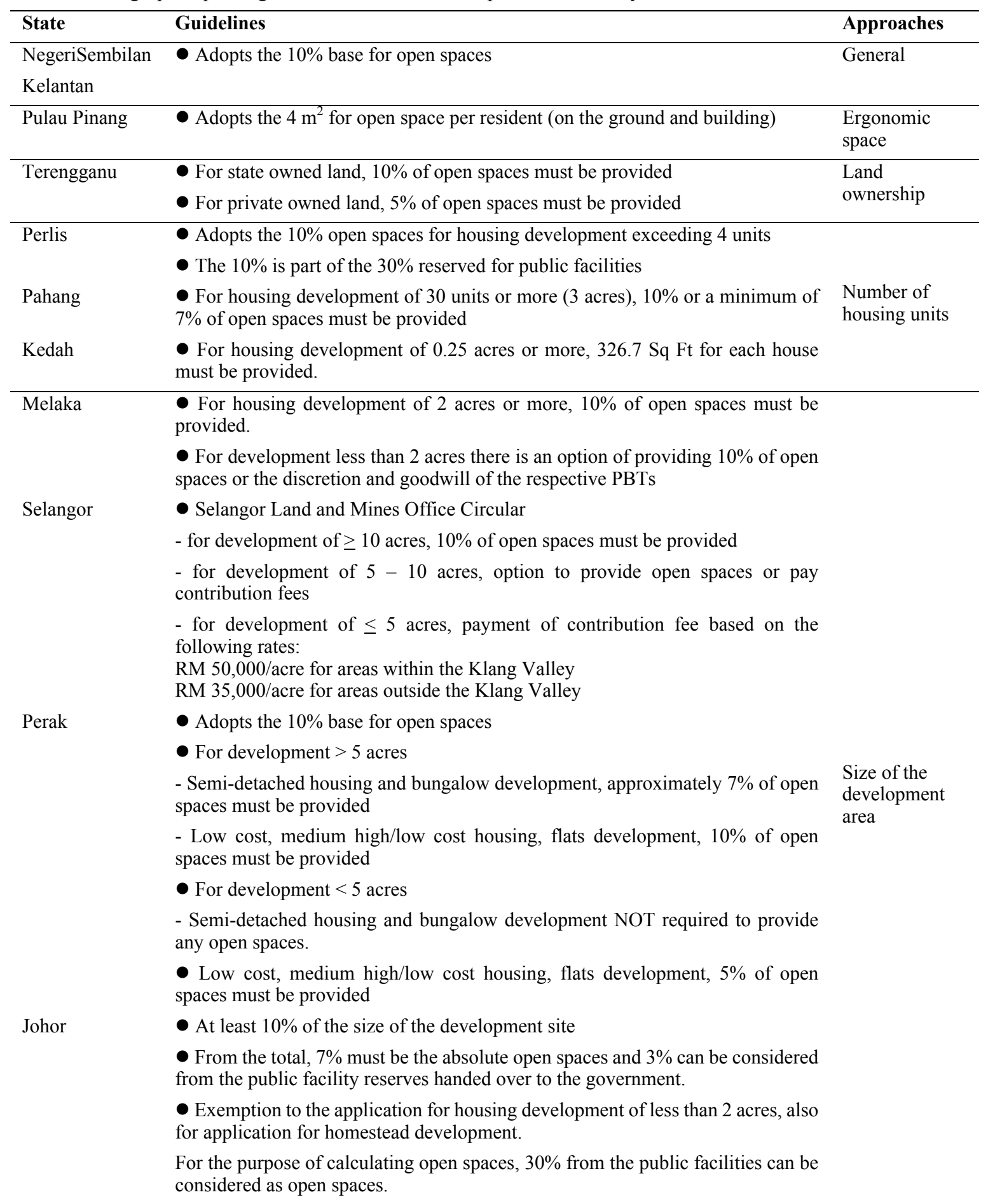

Source: Federal department of town and country planning, Peninsular Malaysia (2009).

In Perak; the emphasis is on the provision of open spaces for high-rise housing development. Developers are not given any leniency in the provision of open spaces for high-rise housing development. Last but not least, the state of Johor breaks down the percentages for the provision of open spaces into 'absolute open spaces' and public facilities. 'Absolute open space' here means a completely functional open area.

Undoubtedly, the five approaches discussed have their own issues and problems. Whichever the approach adopted, it should promote the provision of sustainable open spaces for public use. However, each approach adopted must 
be implemented with a single goal, which is to ensure that the provision of open spaces in housing developments cannot be easily neglected.

\section{Method}

Since the research focus on policy implementation by the decision maker and planning administrative at the local level, respondents involved in the survey were the town planning officers and their technical assistants. The survey manages to obtain a sample size of 240 units with response rates of $52.6 \%$ from 98 local authorities in Peninsular Malaysia. The questionnaire survey was conducted for a period of three months from $1^{\text {st }}$ January 2011 and ended on $31^{\text {st }}$ March 2011 using a mail method.

Since the study will be focusing on the execution of the Planning Standards and Guidelines for Open Space and Recreational Areas (JBPD 7/2000) among local authorities in Peninsular Malaysia, for the purpose of writing this guideline will subsequently be referred as the JBPD 7/2000 guideline. The first section of the research looks into personal information of the respondents such as gender, age, job position and council status. Section 1 of the survey will include questions with regards to dissimilarity in application of open space policy among LAs, Section 2 will be discussing on independent policy implemented by the states in Peninsular Malaysia. Finally, Section 3 will talk about the effectiveness of the JBPD 7/2000 guideline.

\section{Results}

The research findings indicate male respondents formed the majority $(59.6 \%)$ of the responds; the remaining $40.4 \%$ are female respondents. The average age of respondents was 35 years old. The planning officers formed the major group of the respondents with $57.5 \%$ while the remaining $42.5 \%$ was the response of the technical assistants. The respondents involve in the survey work in three categories of council status which are city council, municipal council and district council. Majority of the respondents work in a municipal council that comprises of $43.9 \%$; followed by a district council that is $43.1 \%$ and $13 \%$ out of the respondents work in a city council.

\subsection{Different Application of Open Space Policy by LAs}

The first section of the survey was to investigate the differences in the application of open space policy guideline by the LAs from 11 states in Peninsular Malaysia. Two questions were asked to draw out respondent's opinion with regards to the differentiation; (1) do the respondent's aware of dissimilarity in the application of JBPD 7/2000 guideline among LAs; and (2) the differences in application of JBPD 7/2000 is due to the development situation in the jurisdiction.

Table 2. Dissimilarity in application of the JBPD 7/2000 guideline

\begin{tabular}{lcc}
\hline & Frequency & Percent \\
\hline Disagree & 5 & 2.1 \\
Not sure & 13 & 5.4 \\
Agree & 220 & 91.7 \\
Total & 238 & 99.2 \\
\hline
\end{tabular}

As expected, majority of respondents stated that they are aware of the differences in application of JBPD 7/2000 guideline among LAs. Table 2 shows high percentage of $91.7 \%(n=220)$ agree with the statement. Out of 240 respondents only 5 was not aware of the differences and 13 was not sure. The result provides initial observation; majority of the respondents are highly experience planning professionals. A small percentage of $2.1 \%$ that was not aware of the differences was probably young and inexperienced respondents.

Table 3. Difference in application is due to development situation

\begin{tabular}{lcc}
\hline & Frequency & Percent \\
\hline Disagree & 6 & 2.5 \\
Not sure & 68 & 28.3 \\
Agree & 162 & 67.5 \\
Total & 236 & 98.3 \\
\hline
\end{tabular}


Table 3 also indicates high percentage in term of agreement - more than half of the respondents agree (67.5\%) the differences in application of the JBPD 7/2000 guidelines is because of development situation. The remaining $32.5 \%$ was not sure and disagree with explanation of diverse application of the JBPD 7/2000 guideline by LAs in Malaysia is because of distinction in development pace. The initial result from the two questions can be concluded; the JBPD 7/2000 is standard open space guideline used by the states government for the purpose of open spaces provision. However, through the respective LAs the guideline has been 'adopted and adepted'to suit with the development situation in jurisdiction.

\subsection{Different Guideline Approaches Implemented by the State Governments}

Section 2 of the survey focus on independent policy implemented by the states in Peninsular Malaysia. As been indicated in Table 1, there are five basic types of approaches that the state governments adapt from the JBPD $7 / 2000$ guideline pertaining to open space provision. The approaches was different and independent therefore what is seem to be appropriate to be implemented in one state might not be suitable to other. Consequently, the state government needs to determine the most appropriate procedure for the use in their respective areas. In Section 2, respondents were asked to select the open space guideline application that is put into practice by the LAs they work with. The purpose of the question is to calculate the percentage for each methods of open space policy application used. Before proceeding with the question, the research needs to explore the distribution number of LAs for the 11 states in Peninsular Malaysia.

Table 4. Number of local authorities according to state and status

\begin{tabular}{llcccc}
\hline & STATE & $\begin{array}{c}\text { City } \\
\text { Council }\end{array}$ & $\begin{array}{c}\text { Municipal } \\
\text { Council }\end{array}$ & $\begin{array}{c}\text { District } \\
\text { Council }\end{array}$ & TOTAL \\
\hline 1. & KELANTAN & 0 & 1 & 11 & 12 \\
2. & NEGERI SEMBILAN & 0 & 3 & 5 & 8 \\
3. & PULAU PINANG & 0 & 2 & 0 & 2 \\
4. & TERENGGANU & 1 & 2 & 4 & 7 \\
5. & KEDAH & 1 & 3 & 7 & 11 \\
6. & PERLIS & 0 & 1 & 0 & 1 \\
7. & PAHANG & 0 & 3 & 8 & 11 \\
8. & MELAKA & 1 & 3 & 0 & 4 \\
9. & PERAK & 1 & 4 & 10 & 15 \\
10. & JOHOR & 1 & 6 & 8 & 15 \\
11. & SELANGOR & 2 & 6 & 4 & 12 \\
& TOTAL & 7 & 34 & 57 & 98 \\
\hline
\end{tabular}

Source: Local Government Department, Ministry of Housing and Local Government (2011).

Table 4 presents the statistics of LAs based on their status that are bounded under Act 172. It was observed the state of Kelantan, Kedah, Pahang, Perak, Johor and Selangor have more than 10 LAs for each state regardless of council status. Three states has the least number of LAs which are Perlis (1); Pulau Pinang (2); followed by the state of Melaka (3). Last but not least, the state of Terengganu has 7 LAs and the state of Negeri Sembilan has 8 LAs. The number of LAs in each state is indeed important in the survey because it will affect the estimated potential respondents.

Table 5 shows the percentage of guideline application that was put into practice by respondents involves in the survey. Out of five types guideline approaches used by the 11 states in Peninsular Malaysia; total of land development method scores the highest percentage of $50.9 \%(n=112)$. In this method, the size of open spaces in an area will be based on calculation; 10 percent out of total development size.

As expected this method will have the highest fraction because four states adopted this approach which is Melaka, Perak, Johor and Selangor. The second highest percentage score is the total of housing unit method and three states opted for this approach which is Kedah, Perlis and Pahang with $21.4 \%(n=47)$ of respondents indicated this technique is put into practice by the LAs they work with. In this method the amount of open spaces 
need to be provided in a development will depend on the numbers of houses built. The general approach which is implemented by the state of Kelantan and Negeri Sembilan, scores the third highest percentage with $19.5 \%$ ( $n$ $=20$ ) followed by the land ownership approach with $6.4 \%$. $(n=7)$ applied in Terengganu. The lowest percentage of $1.8 \%(n=4)$ is the ergonomic space approach which was implemented by a single state in Peninsular Malaysia; Pulau Pinang. Considering the distribution of LAs in Table 3 confirm the percentage and number of responses obtained in the survey. It was difficult to accomplish higher number of respondents in the states that have a few LAs. Other than that the types of guideline application opted by the state government also play important roles in anticipating the result.

Table 5. Open space guideline application

\begin{tabular}{lll}
\hline & $\mathrm{N}$ & Percent of Cases \\
\hline General & 43 & 19.5 \\
Ergonomic Space & 4 & 1.8 \\
Land Ownership & 14 & 6.4 \\
Total of Housing Unit & 47 & 21.4 \\
Total of Land Development & 112 & 50.9 \\
Total & 220 & 100 \\
\hline
\end{tabular}

\subsection{Effectiveness of the JBPD 7/2000 Guideline}

Although the 11 states have options of implementing the open space policy in different ways the JBPD 7/2000 guideline plays an important role to prevail the general parameters with regards to open space provisions. As an attempt to investigate views on the effectiveness of the JBPD 7/2000 guideline among LAs town planners and technical assistants; series of questions were asked to elicit their opinion with regards to the stated guideline. The identified attributes listed to measure effectiveness in the study are (1) do the respondents feel the guideline is important for open space planning; (2) to what extend the respondent think the guideline is a useful planning tool; (3) usage of the guideline as a reference material in daily work.

Table 6. Important policy

\begin{tabular}{lcc}
\hline & Frequency & Percent \\
\hline Disagree & 66 & 27.5 \\
Not sure & 45 & 18.8 \\
Agree & 128 & 53.3 \\
Total & 239 & 99.6 \\
\hline
\end{tabular}

As expected; majority of respondents feel that JBPD 7/2000 guideline is indeed a very important guideline. Table 6 shows a total of $53.3 \%(n=128)$ agree the guideline is indeed significant for open space planning. The remaining $27.5 \%$ disagree with the statement and $18.9 \%$ was unsure. Even though there was a big difference in agreement for this, Table 7 indicates almost half of the respondents $(49.2 \%, n=118)$ agree the guideline is a useful planning tool. This is because the guideline indicates detail parameter pertaining to open space planning. The results provide an idea that the guideline is considered fundamental with respondent's nature of work. The JBPD 7/2000 guideline is an essential reference material in the preparation of conducive open spaces.

The effectiveness of the guideline further examined with regards to its usage as a reference material. The result indicated $44.6 \%(n=107)$ of respondents stated they always use the JBPD 7/2000 guideline in their daily work and $29.6 \%$ indicated they seldom use the guideline. Of those who responded, only $59(24.6 \%)$ said they never use the JBPD 7/2000 guideline. The research predicted this is probably because of the nature of their work. The Planning Department in LAs have various units such as planning control, GIS and research and development unit. Therefore, it was envisaged respondents who never use the guideline does not involve in process of planning permission. 
Table 7. Useful planning tool

\begin{tabular}{lcc}
\hline & Frequency & Percent \\
\hline Disagree & 49 & 20.4 \\
Not sure & 68 & 28.3 \\
Agree & 118 & 49.2 \\
\hline Total & 235 & 97.9 \\
\hline
\end{tabular}

The research further interested to know usage rate among three council groups namely; city council, municipal council and district council. Based on the descriptive analysis obtained, there were differences observed between the means. District council had achieve the highest means score $(\mathrm{M}=4.76, \mathrm{SD}=1.660)$ followed by municipal council $(\mathrm{M}=4.83, \mathrm{SD}=1.700)$ and city council $(\mathrm{M}=3.77, \mathrm{SD}=1.765)$. However it should be noted; higher mean scores for the district council group does not signify respondents from other councils is less using the JBPD 7/2000 guideline. It was observed higher number of respondents a single council group will contribute to higher mean scores. Other than that, the output of Levene' for equality of variances test confirmed the data does not violate the homogeneity of variance assumption with $p$ value of 0.053 .

Table 8. Usage of the JBPD 7/2000 Guideline

\begin{tabular}{lccccc}
\hline & Sum of Squares & df & Mean Square & F & Sig. \\
\hline Between Groups & 35.969 & 2 & 17.985 & 6.855 & .001 \\
Within Groups & 611.264 & 233 & 2.623 & & \\
\hline Total & 647.233 & 235 & & & \\
\hline
\end{tabular}

At first a one way analysis of variance was conducted to examine the usage rate among the three council groups. An interesting finding was discovered in term frequency of usage by respondents working in city council, municipal council and district council. The result in Table 8 indicates; there was a significant difference in the usage of the guideline among the groups $[\mathrm{F}(2,233)=6.855, p=0.001]$. Despite reaching statistically significance the effect size, calculated using eta squared was 0.0555 . This mean only $5.55 \%$ of the variances in JBPD 7/2000 guideline usage is explained by the difference among the levels within the council status. According to the guidelines proposed by Cohen (1988, p.284-7) for interpreting the value of eta squared; 0.0555 is considered small. In addition, a Post Hoc comparison using Scheffe test was carried out to identify the differences occur between the three council groups. The output of the Post Hoc test indicated that the difference in the mean scores between city council $(\mathrm{M}=3.77, \mathrm{SD}=1.765)$ and municipal council $(\mathrm{M}=4.83, \mathrm{SD}=1.700)$ and between city council $(\mathrm{M}=3.77, \mathrm{SD}=1.765)$ and district council $(\mathrm{M}=4.76, \mathrm{SD}=1.660)$ are statistically significant with $p=0.001$. However, the difference between municipal council $(\mathrm{M}=4.83, \mathrm{SD}=1.700)$ and district council $(\mathrm{M}=4.76, \mathrm{SD}=1.660)$ was observed to be not statistically significant.

\section{Discussion}

Clearly, policies with respect to open spaces adopted by the states in Peninsular Malaysia differ from one another. This is because the JBPD 7/2000 guideline issued by FDTCP is a general guideline. The guideline describes the need for open spaces in every development. It outlines several approaches that must be adopted by all parties involved in ensuring the provision of open spaces for public use. For that reason, all state governments have taken the initiative to produce guidelines specifically to assist their respective LAs to carry out their tasks in realizing the government's vision for Malaysia to become a garden nation. High awareness level among town planners and technical assistants regarding different application of the JBPD 7/2000 guideline was expected since as a decision maker and planning administrator in the LAs; both town planners and technical assistants are the main implementer of the open space policy at their jurisdiction. Therefore, respondents are aware open space policy adopted by the states governments is different and independent. Apparently several approaches that have been discussed will raise issues and problems.

Even though the FDTCP has set a policy of 10 percent for open spaces for each development application, the 10 percent policy of open spaces for each development maybe difficult to implement in states with developed status. A good example is Pulau Pinang, with its excellent geographical location and very rapid development. However, 
the size of the main areas on the island is rather small making it difficult for Pulau Pinang to cope with the rapid development in the state. This has resulted in most housing developments being high-rises. The state government has provided an alternative, which is the provision of 'roof top gardens' to replace the open spaces. Roof top gardens seem to be a good solution to overcome the land shortage in Pulau Pinang. However, roof top gardens in the context of the definition of open spaces in the Town and Country Planning Act 1976 (Act 172), do not conform to open spaces for public use as highlighted in the said Act. Roof top gardens are clearly not for public use because it is the exclusive rights of the owner of the high-rise.

The research also interested to investigate the effectiveness of the JBPD 7/2000 guideline in the opinion of LAs town planners and technical assistants. However, review of Koomen, Dekkers et al. (2008) states, the effectiveness of a policy is difficult to be analysed. This is because according to Ingram and Mann (1980) the success or failure of an established policy is very subjective depending on the person who evaluates it. Based on the result obtained, it can be assumed the JBPD 7/2000 guideline has been productively helping LAs planning professionals in the matter of open spaces planning. In term of usability of JBPD 7/2000 guideline between councils, the researcher expects the differences occur between respondent's working in city council and district council is because of development situation. It is well known that development rate in rural areas are less compare to urban areas therefore respondent's working in city council might receive more application for planning permission. Thus it will lead to more usage of the JBPD 7/2000 guideline for reference purposes. Therefore higher usage of the guideline as a reference material is expected from respondents working in urban areas because the planning administration and decision maker need to be more stringent in term of open space matter since urban areas are experiencing land shortage and high demand from the public.

On the other hand, there are several factors that contribute to the ineffectiveness of policies initiated by the government. The demand or the need for open spaces is a factor in determining the effectiveness of an implemented policy. Population density, especially in large towns, causes residents to demand provision of more open spaces for them to release stress from the daily hustle and bustle as well as congestion of urban environments. It is believed that LAs in states experiencing rapid development like Johor are more stringent in ensuring that the open space policy is implemented properly. The Johor state government stresses the need for a 7 percent absolute open space out of the 10 percent required of developers. The "no compromise" approach by the Perak state government requiring developers to provide open spaces irrespective of the development size should be an exemplary. There are other scenarios in states experiencing slow economic development as in Perlis and Kelantan. The need for open spaces by residents in the two states is not as critical as that faced by the residents of Selangor and Pulau Pinang. This may be due to an abundance of unused areas, and subsequently, the states possess plenty of green areas. The LAs are believed to be concentrating on the main affairs such as formulating strategies and ensuring the provision of good infrastructure in their respective areas. Thus, it is not surprising that the implementation of policies with respect to open spaces in these states is not as stringent compared to that for states that are experiencing more rapid development.

\section{Conclusion}

It can be summarized that the above discussion clearly shows that the different applications and implementation of the provision of open spaces policies by the states implied in the Town and Country Act 1976 (Act 172) may have several implications within the context of the government's target to provide 2 hectares of open spaces for every 1,000 residents as achieved by developed countries (as; New York, Melbourne and Toronto). In line with Vision 2020 for Malaysia to become a developed country, several important steps must be taken to ensure that this target can be achieved. The issuance of the JBPD 7/2000 guideline by FDTCP is a prudent move to ensure that the provision of open spaces for public use is not neglected. However, a uniform guideline should be issued by FDTCP to standardize the application and implementation of open spaces policies in all states. The uniform guideline should focus on the various types of development rate undergone by the states. This is difficult task but important in order to avoid the implementation of open spaces policy in states that are not facing a critical need for open spaces. FDTCP should not focus solely on the total average of open spaces for each state, but should recognize the differences of size and growth rates. In other words, the policy formulated should be responsive to growth pressures and at the states level the willingness to change the state policy environments. As discussed, the introduction of the alternative roof top gardens to replace the provision of open spaces for high-rise housing in Pulau Pinang is an effort at conforming to the criteria in terms of definition, and thus the definition of open spaces as in Act 172 and its related policy application should be expanded 


\section{Acknowledgements}

The authors would like to thank the Research and Development Unit, Federal Department of Town and Country Planning, Peninsular Malaysia (FDTCP) for the information and support given.

\section{References}

Ainul Jaria, M., \& Bashiran Begum, M. A. (2009). Powers of the local authority in regulation land planning and development control: whither control. Journal of the Malaysian Institute of Planners, 7, 133-147.

Allen, R. E. (1991). The Concise Oxford dictionary of current English (8th ed.). Oxford: Clarendon Press.

Bengston, D. N., \& Fletcher, J. O. (2004). Public policies for managing urban growth and protecting open space: policy instruments and lessons learned in the United States. Landscape and Urban Planning, 69(2-3), 271-286.

Cohen, J. (1988). Statistical power analysis for the behavioural science (2nd ed., pp. 284-287). Lawrence Erlbaum Associates. http://dx.doi.org/10.1016/j.landurbplan.2003.08.007

Department of Statistics Malaysia. (2000). Urbanisation and Urban Growth In Malaysia. - Monograph Series No. 4. Department of Statistics, Kuala Lumpur.

Department of Town and Country Planning. (1976). Town and Country Planning Act, Act 172. International Law Book Services, Malaysia.

Department of Town and Country Planning. (2005). Garis Panduan Piawaian Perancangan Tanah Lapang dan Rekreasi (JPBD 7/2000). Ministry of Housing and Local Government, Peninsular Malaysia, Kuala Lumpur.

Department of Town and Country Planning. (2009). Research and Development Planning. Kuala Lumpur, Ministry of Housing and Local Government, Peninsular Malaysia, Kuala Lumpur.

Girling, C. L., \& Helphand, K. I. (1994). Yard street park the design of suburban open space. Canada: John Wiley \& Sons, Inc.

Goh, B. L. (1991). Urban planning in Malaysia: history, assumptions and issues. Petaling Jaya: Tempo Publishing (M) Sdn. Bhd.

Grose, M. J. (2009). Changing relationships in public open space and private open space in suburbs in south-western Australia. Landscape and Urban Planning, 92(1), 53-63. http://dx.doi.org/10.1016/j.landurbplan.2009.02.006

Ingram, H. M., \& Mann, D. E. (1980). Why policies succeed or fail. London: Sage Publication.

Koomen, E., Dekkers, J., \& van Dijk, T. (2008). Open-space preservation in the Netherlands: Planning, practice and prospects. Land Use Policy, 25, 361-377. http://dx.doi.org/10.1016/j.landusepol.2007.09.004

Lee, L. M., \& Abdul Mutalip, A. (1990). Town planning in Malaysia: history and legislation. Penang: Universiti Sains Malaysia.

Lukman, Z. M., Mohd Yusoff, H., \& Azmi, A. (1999). Urban crime: Planner's obligation. Habitat Malaysia Human Settlements Journal of Malaysia Vol., 2, 37-45.

Map of Malaysia. (2008). Malaysia Inland Waterway Transport System in Sarawak. Published by United Nations Development Programme (UNDP), Malaysia.

Maruani, T., \& Amit-Cohen, I. (2007). Open space planning models: A review of approaches and methods. Landscape and Urban Planning, 81, 1-13.

Phang, S. M. (2006). Local government. In A. Zakaria (Ed.). Government and Politics (1940 - 2006) the Encyclopedia of Malaysia. Kuala Lumpur: Archipelago Press. http://dx.doi.org/10.1016/j.landurbplan.2007.01.003

Zakaria, A. (2006). Federal territories. In A. Zakaria (Ed.). Government and Politics (1940 - 2006$)$ the Encyclopedia of Malaysia. Kuala Lumpur: Archipelago Press.

\section{Copyrights}

Copyright for this article is retained by the author(s), with first publication rights granted to the journal.

This is an open-access article distributed under the terms and conditions of the Creative Commons Attribution license (http://creativecommons.org/licenses/by/3.0/). 